\title{
A CONTRIBUIÇÃO DAS FEIRAS AGROECOLÓGICAS NA UFMS/CAMPUS II E NO CONDOMÍNIO DON EL CHALL PARA A SOBERANIA ALIMENTAR EM TRÊS LAGOAS/MS
}

\author{
LA CONTRIBUCIÓN DE LAS FERIAS AGROECOLÓGICAS EN LA \\ UFMS/CAMPUS II Y EN EL CONDOMINIO DON EL CHALL PARA \\ LA SOBERANÍA ALIMENTARIA EN TRES LAGOAS/MS \\ THE CONTRIBUTION OF THE AGROECOLOGICAL FAIRS IN \\ UFMS / CAMPUS II AND IN THE CONDOMINIUM DON EL \\ CHALL FOR FOOD SOVEREIGNTY IN TRES LAGOAS/MS
}

\author{
Glaucimar Alves Pinha \\ Bolsista UFMS/PIBIC/CNPq \\ glaucimar.pinha@gmail.com

\section{Rosemeire Aparecida de Almeida \\ Docente UFMS/CPTL raaalm@gmail.com}

\begin{abstract}
Resumo: A comercialização dos excedentes gerados pela agricultura familiar no Brasil é marcada pela deficiência de uma política agrícola que garanta preço justo para quem produz e qualidade para quem consome, sendo essa perda de controle sobre os recursos e, portanto, de soberania alimentar um dos resultados da Revoluçáo Verde. Buscando contribuir para a superação desta crise é que foram desenvolvidos projetos na UFMS/Três Lagoas de fomento aos canais curtos de comercializaçáo, no caso as feiras de base agroecológicas provenientes dos assentamentos rurais. A pesquisa objetivou-se acompanhar e analisar os principais resultados, para agricultores e consumidores, das Feiras agroecológicas promovidas pela Associação dos Agricultores Familiares do Assentamento "20 de Março" no ambiente universitário da UFMS/CPTL e no Condomínio Don El Chall. A pesquisa realizou-se por meio de estudos teóricos e aplicação de questionário estruturado e não estruturado. Conclui-se que a implantação das feiras melhorou as condiçóes de renda dos agricultores-feirantes, diminuiu a distância entre agricultor e consumidor e melhorou o diálogo favorecendo o conhecimento dos caminhos da soberania alimentar.
\end{abstract}

Palavras-chave: Agroecologia. Soberania Alimentar. Feiras, Assentamento 20 de Março. Três Lagoas. 
Resumen: La comercialización de los excedentes generados por la agricultura familiar en Brasil está marcada por la deficiencia de una política agrícola que garantice precio justo para quien produce y calidad para quien consume, siendo esa pérdida de control sobre los recursos y, por lo tanto, de soberanía alimentaria uno de los resultados de la Revolución Verde. Buscando contribuir a la superación de esta crisis es que se desarrollaron proyectos en la UFMS / Três Lagoas de fomento a los canales cortos de comercialización, en el caso de las ferias de base agroecológicas provenientes de los asentamientos rurales. La investigación se objetivó acompañar y analizar los principales resultados, para agricultores y consumidores, de las Ferias agroecológicas promovidas por la Asociación de los Agricultores Familiares del Asentamiento "20 de Marzo" en el ambiente universitario de la UFMS/ CPTL y en el Condominio Don El Chall. La investigación se realizó por medio de estudios teóricos y aplicación de cuestionario estructurado y no estructurado. Se concluye que la implantación de las ferias mejoró las condiciones de ingreso de los agricultores-feriantes, disminuyó la distancia entre agricultor y consumidor y mejoró el diálogo favoreciendo el conocimiento de los caminos de la soberanía alimentaria.

Palabras clave: Agroecologia. Soberanía Alimentaria. Ferias. Asentamiento 20 de Marzo. Três Lagoas.

Abstract: The commercialization of the surpluses generated by family farming in Brazil is marked by the deficiency of an agricultural policy that guarantees a fair price for those who produce, and quality for those who consume, and this loss of control over resources and, therefore, of food sovereignty, is one of the results of the Green Revolution. Aiming to contribute to overcome this crisis, projects were developed at UFMS / Três Lagoas to promote short marketing channels, in this case the agroecological based fairs from rural settlements. The objective of this research was to monitor and analyze the main results for farmers and consumers of the agroecological fairs promoted by the Association of Family Farmers of the "20 de Março" Settlement, in the university environment of UFMS / CPTL, and in the Condominium Don El Chall. The research was carried out through theoretical studies and the application of structured and no structured questionnaires. It was concluded that the implementation of the fairs improved the farmers' income conditions and reduced the distance between farmer and consumer, improving their dialogue, and favoring the knowledge of the paths for food sovereignty.

Keywords: Agroecology. Food sovereignty. Fairs. 20 de Março Settlement. Três Lagoas.

\section{INTRODUÇÃO}

A comercialização dos excedentes gerados pela agricultura familiar no Brasil sempre foi marcada pela deficiência de uma política agrícola que garanta preço justo para quem produz e qualidade para quem consome, sendo essa perda de controle sobre os recursos um dos resultados da Revolução Verde. Ou seja, de um lado perda de renda e empobrecimento dos agricultores familiares, de outro, alimentos caros ou de baixa qualidade nos centros urbanos. 
A fim de contribuir localmente para correção deste desequilíbrio, desde 2015 a UFMS/ Campus de Três Lagoas vem apoiando os assentados por meio de projetos de pesquisa e

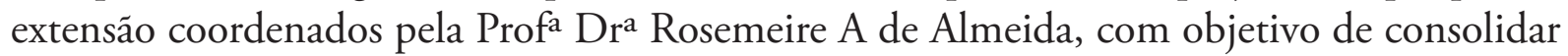
espaços de comercialização direta da produção dos assentados de reforma agrária, e demais agricultores familiares, como ação essencial para manutenção do modo de vida camponês.

Por conseguinte, são essas iniciativas de comercialização direta, em especial as feiras, o objeto de análise deste texto na busca de compreensão das contribuiçóes destas açóes para a soberania alimentar no campo e na cidade.

Os sujeitos analisados são assentados-feirantes que desde 2009 vivem no projeto de reforma agrária "20 de Março", localizado a 36 quilômetros de Três Lagoas/MS. Atualmente, as feiras constituem a base da comercialização do assentamento e têm permitido a reprodução e permanência na terra dos agricultores familiares. As estratégias de comércio e a melhoria da capacidade de produção têm sido fundamentais para geração de renda monetária e avanço da soberania alimentar.

Os assentados produzem baseados em saberes agroecológicos, substituindo os agrotóxicos e adubos químicos por um manejo ecológico com caldas defensivas e biofertilizantes, resultando em alimentos saudáveis e seguros. Afastando-se, dessa forma, do modelo de agricultura adotado na Revolução Verde, responsável por provocar grandes consequências ambientais como erosão do solo, desertificação, poluição por agrotóxicos e perda de biodiversidade que causam impactos ambientais, econômicos e sociais.

O uso de agroquímicos na agricultura moderna começou no final do século XIX, quando pesquisadores europeus, como Liebig, da Alemanha, considerado "o pai da química agrícola”, e Boussingault, da França, apostaram na química para incrementar a produção agrícola, em contraposição a Humboldt, que propunha o uso de biofertilizantes. Esse foi o momento histórico no qual as duas vertentes de produção de alimentos (agricultura convencional X agricultura ecológica) se formaram e passaram a se distanciar, dando início à contradição entre o discurso dos governos da Europa e Estados Unidos em prol da segurança alimentar e sua opção pela produção de alimentos como negócio. (CRIVELLARO, 2008, p. 05)

Logo, o sistema agroecológico é uma das alternativas que possibilitam reverter esse quadro, pois essa prática de produção valoriza os saberes camponeses e respeita os ciclos da natureza contribuindo para a manutenção e aumento da biodiversidade. (ALMEIDA, 2017).

No entanto, a agroecologia ainda é pouco divulgada porque impera o modelo de produção convencional, aquele da agricultura química, dominado por grandes corporaçóes que favorecem a comercialização, industrialização e concentração de terra. Consequentemente, o consumidor opta por esses alimentos processados tanto por conta do marketing massivo como pelas urgências do modo de vida moderno. Neste modelo o consumidor náo conhece a origem do produto consumido e muito menos quem o produz.

Neste sentido, Darolt (2012) explica: 
O advento da alimentação industrializada e o estilo de vida moderno ajudaram a afastar quem produz de quem consome. A maioria das pessoas hoje abastece sua cozinha com alimentos prontos e altamente processados. É cada vez maior o distanciamento entre o mundo rural e o urbano. (p. 13).

Portanto, umas das vantagens das feiras agroecológicas é que possibilitam a reconexão dos agricultores com os consumidores, estabelecendo contato e diálogos a respeito tanto da origem desses alimentos como do modo de vida dos agricultores, uma vez que esses elementos influenciam na produção dos alimentos. Esse processo favorecesse ainda a identificação e valorizaçáo da reforma agrária, recriando uma cultura consciente de conhecer o alimento a partir de sua localidade, do seu preço justo e, acima de tudo, das pessoas que cultivam esse alimento.

\section{CAMINHOS DA PESQUISA: TEORIA E PRÁTICA}

Os estudos teóricos foram realizados na Universidade Federal de Mato Grosso do Sul, Campus II, no Laboratório de Estudos Territoriais (Labet), e o trabalho de campo nas feiras dos assentados realizadas na UFMS, Campus II, e no Condomínio Don El Chall, em Três Lagoas/MS.

A pesquisa possui duas abordagens: a primeira privilegia a construção do referencial teórico-metodológico por meio de levantamento de livros e artigos que se relacionam à temática em estudo, qual seja agricultura familiar, feiras agroecológicas e soberania alimentar. Assim, a base teórica está assentada nos autores Altieri (2004), Darolt (2012), Almeida $(2014,2017)$, que colaboram para conceituar o objeto de estudo e analisar os resultados obtidos no trabalho de campo.

A segunda abordagem se refere à delimitação do grupo de estudo dentro da Associação dos Agricultores Familiares do Assentamento "20 de Março" para coleta de dados e informaçóes No caso, foram selecionados os assentados que participam diretamente das Feiras.

Por sua vez, a coleta de dados se divide em dois instrumentos: questionário estruturado e não estruturado (entrevista).

Por meio dos estruturados realizou-se a aplicação de questionários no universo de famílias que compóem o grupo das hortas da Associação dos Agricultores Familiares do Assentamento "20 de Março", e que participam da Feira no CPTL/Unidade II e no Condomínio Don El Chall.

O questionário visava apreender as motivações e expectativas em relação às Feiras, bem como averiguar os resultados econômicos de melhoria da renda familiar.

O não estruturado (entrevista) foi realizado com consumidores nas Feiras visando registar o grau de satisfação, entender possíveis limites e sugestóes para consolidação e busca de novos espaços.

O critério para escolha dos consumidores para entrevista foi aleatório de acordo com a disponibilidade no período de aplicação dos questionários. 
A pesquisa na UFMS Campus II foi realizada no período diurno entre $10 \mathrm{~h} 00$ e $17 \mathrm{~h} 00$ e no Condomínio Don El Chall no período noturno das $17 \mathrm{~h} 00$ às $20 \mathrm{~h} 00$. A aplicação dos questionários foi realizada durante os meses de outubro a novembro de 2017.

\section{QUEM SÃO OS ASSENTADOS-FEIRANTES: VIDA E TRABALHO NA TERRA}

As feiras analisadas são mantidas e realizadas pelo grupo de famílias assentadas que trabalham com hortas no projeto de reforma agrária "20 de Março", localizado em Três Lagoas/ MS. O referido projeto de assentamento foi criado em 2008 pelo Instituto Nacional de Colonização e Reforma Agrária (INCRA), com imissão de posse no ano de 2009. É composto por 69 famílias que vivem numa área de 1.490,3583 ha. (MEDEIROS, ALMEIDA, 2016).

Segundo Medeiros, Almeida (2016), a luta pela terra ocorreu, num primeiro momento, com a formação do acampamento "Moeda" em 2003, composto inicialmente por 362 famílias, sendo assim denominado por se localizar próximo ao Córrego do Moeda na BR 158. Em 2006, parte do acampamento se deslocou para o Córrego Pinto, onde cerca de 100 famílias se estabeleceram até 2008. Posteriormente, foram para a fazenda Arapuá que foi desapropriada em 2009 para a criação do Assentamento "20 de Março". O nome do Assentamento homenageia a data de entrada na terra das famílias, após a imissão de posse obtida pelo INCRA.

Ainda de acordo com as autoras, desde 2009 as 69 famílias vêm lutando para permanecer na terra, tendo em vista que a energia elétrica foi instalada somente em 2016. Em relação a água, os assentados relataram que houve uma demora de um ano e meio para que todos tivessem acesso efetivo. Tiveram que desenvolver, com a ausência do Estado, uma flexibilidade e capacidade de adaptação frente aos problemas enfrentados. Muitos construíram suas casas com as próprias mãos, apesar de quase ou nenhum conhecimento teórico de engenharia. (MEDEIROS, ALMEIDA, 2016).

Enfim, as dificuldades não foram poucas, como é possível apreender neste trecho:

Além disso, até o momento não receberam financiamentos públicos, não houve liberação de crédito para produção ou mesmo recursos para preparar a terra ou formar área de pastagem. Assim, se veem obrigados a vender sua mão de obra, muitas vezes às empresas de celulose instaladas em Três Lagoas, com quem também fazem "parcerias", para que seja possível sua reprodução social. (MEDEIROS, ALMEIDA, 2016, p. 850).

O processo de transição agroecológica dos assentados do PA 20 de Março se é entendido a partir do que escreve Altieri (2004) quando afirma que a Agroecologia é "uma nova abordagem que integra os princípios agronômicos, ecológicos e socioeconômicos à compreensão e avaliação do efeito das tecnologias sobre os sistemas agrícolas e a sociedade como um todo. Ela utiliza os agroecossistemas como unidade de estudo, ultrapassando a visão unidimensional - genética, agronomia, edafologia - incluindo dimensóes ecológicas, sociais e culturais" (p. 23). O camponês se torna força geradora dos objetivos de desenvolvimento, uma vez que 
"O objetivo é que os camponeses se tornem os arquitetos e atores de seu próprio desenvolvimento" (CHAMBERS, 1983, apud ALTIERI, 2004, p. 27).

Atualmente, no PA "20 de Março" há um grupo de 21 famílias trabalhando com hortas de base agroecológica atendendo mercados institucionais (PAA, PNAE), mercados privados (refeitório industrial) e vendas diretas (Feiras e Grupos de Consumo). Deste grupo das hortas, hoje duas pessoas são responsáveis pelas Feiras em análise.

Portanto, criar e consolidar espaços de comercialização direta da produção dos assentados é essencial para manutençáo do seu modo de vida. Neste sentido, desde 2015, a UFMS/ Campus de Três Lagoas vem apoiando os assentados por meio de projetos de pesquisa e extensão coordenados pela Profa Dra Rosemeire A de Almeida (ALMEIDA, 2017). Por meio dessa ação, primeiramente foi possível a criação de grupos de consumo de sacolas agroecológicas junto à comunidade acadêmica. A partir do êxito desta iniciativa, implantou-se no ano de 2016 a Feira agroecológica na UFMS/CPTL. Consequentemente, uma nova oportunidade de espaço foi conquistada, em 2017, para realização da feira no Condomínio Don El Chall (ALMEIDA, 2017).

\section{AGROECOLOGIA E A CONEXÁO AGRICULTORES E CONSUMIDORES PARA O BEM COMUM}

A Feira Agroecológica na UFMS/Campus II é realizada às terças-feiras no período das 10 h00 às 21 h00 horas, tem como público consumidor: acadêmicos, professores e moradores do entorno. Os produtos ofertados na feira são de grande diversidade, tais como: verduras no geral, frutas, queijo, pão, bolachas, doces, bolos, tubérculos como mostrado nas fotos.

\section{Figura 1 - Feira Agroecológica no CPTL/Campus II}

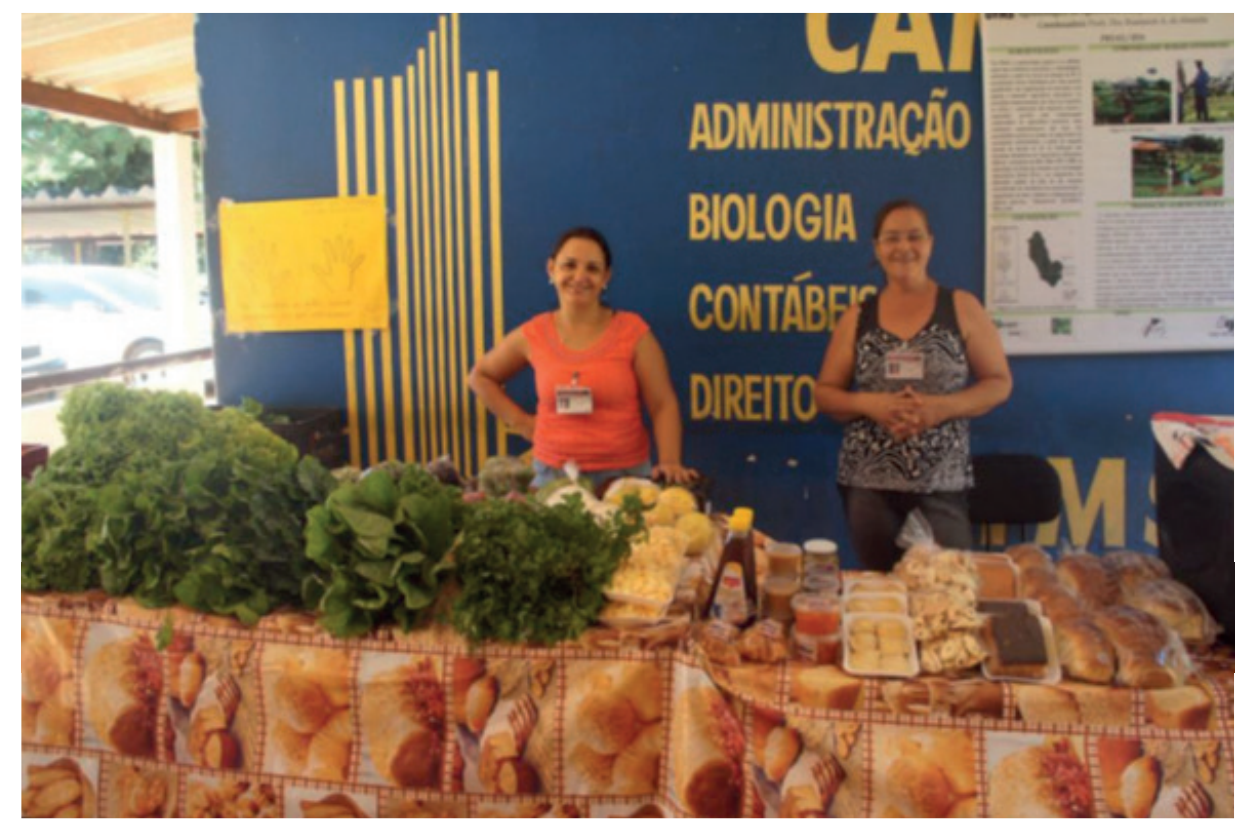

Fonte: CPTL Agroecológico https://www.facebook.com/agroecologiacptl 
A Feira Agroecológica no Condomínio Don El Chall acontece às sextas-feiras, no período das $17 \mathrm{~h} 00$ às $20 \mathrm{~h} 00$ horas, tem como público consumidor moradores do Condomínio. Os produtos ofertados na feira são também de grande variedade, tais como: verduras no geral, frutas, queijo, pão, bolachas, doces, bolos, tubérculos e temperos e etc - como pode ser observado nas figuras 2 e 3.

Figura 2 - Feira agroecológica no Condomínio Don El Chall

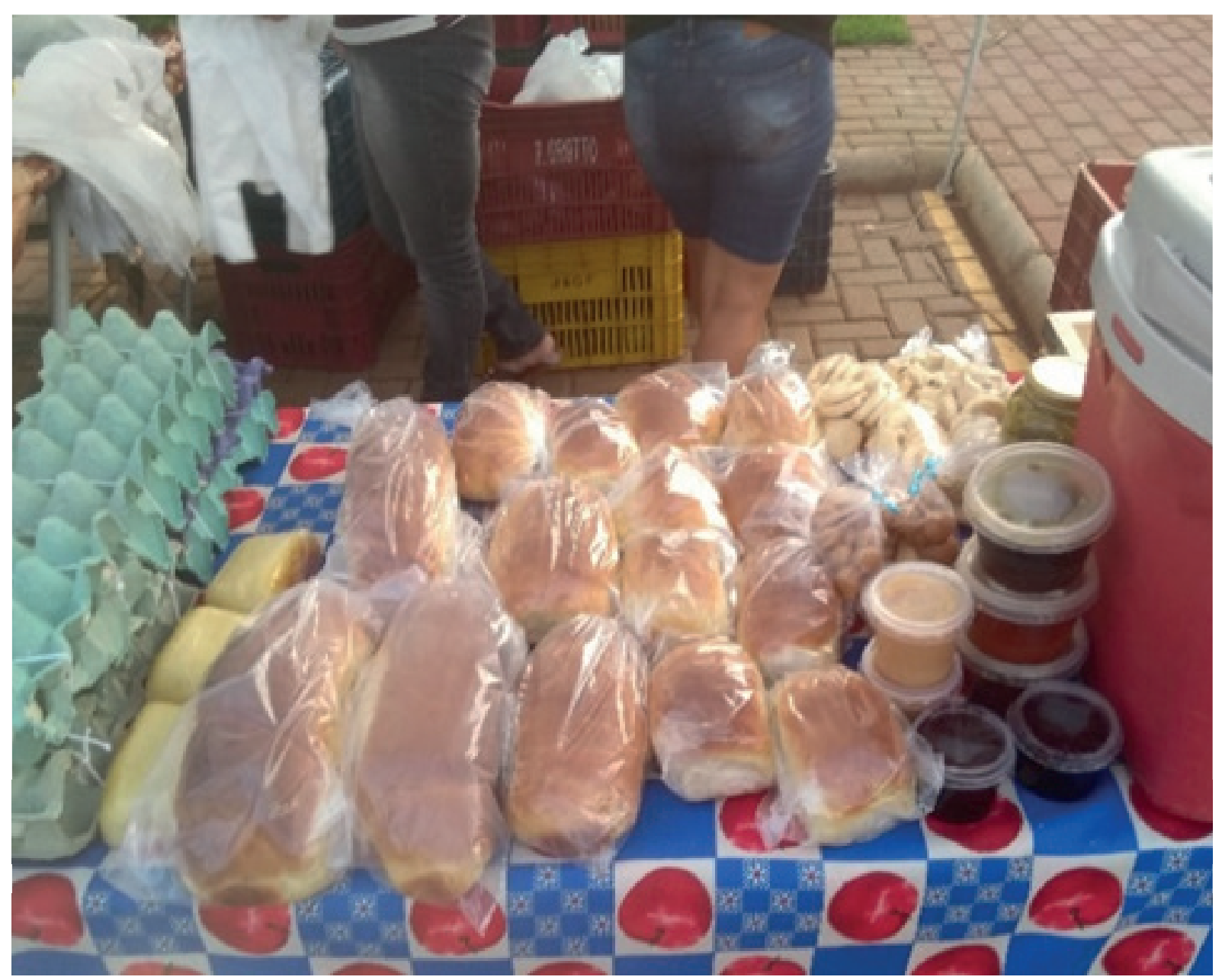

Fonte: Glaucimar Pinha, 2017. 
Figura 3 - Feira agroecológica no condomínio Don El Chall

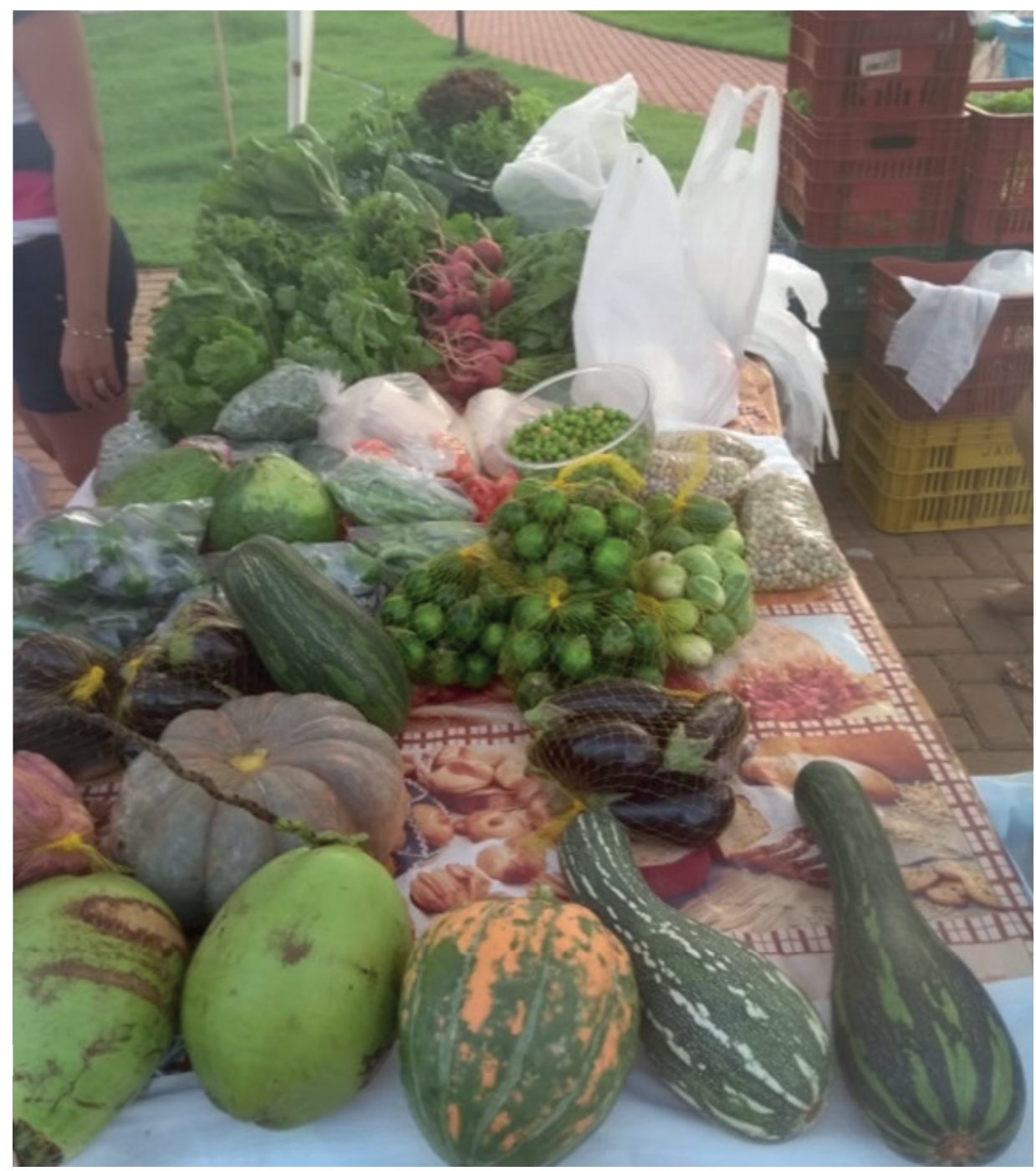

Fonte: Glaucimar Pinha, 2017.

No total foram aplicados 33 questionários junto aos consumidores na UFMS/CPTL, Campus II, e sete questionários junto aos consumidores no Condomínio Don El Chall - a amostragem superior na UFMS é reflexo da existência de um público de consumidores maior neste espaço comparado ao Condomínio. Em relação aos assentados-feirantes, foram entrevistadas duas pessoas que são as responsáveis do grupo das hortas pela comercialização. Destaca-se que nem todas as famílias do grupo das hortas enviam produção para as Feiras, por sua vez a escolha das famílias e produtos direcionados às Feiras é responsabilidade interna do grupo e serão objeto de estudo, posteriormente.

Baseado nos relatos dos assentados-feirantes umas das estratégicas do grupo das hortas agroecológicas é a organização e o vínculo de confiança entre os integrantes, elementos fundamentais para que consigam desfrutar dos benefícios dessa comercialização direta. 
A prática da produção no sistema agroecológico tem ampliado as vendas proporcionando mudança na vida dos assentados-feirantes, em especial com aumento da renda e prestígio social. Portanto, explorar os benefícios da agroecologia como a diversidade dos produtos tem sido uma estratégia de comercialização que promove uma maior oferta em termos de qualidade e variedade dos produtos.

O conhecimento camponês sobre os ecossistemas geralmente resulta em estratégias produtivas multidimensionais de uso da terra, que criam, dentro de certos limites ecológicos e técnicos, a autossuficiência alimentar das comunidades em determinadas regiōes (TOLEDO et al., 1985, apud ALTIERI, 2004, p. 26).

Com base nesse conhecimento agroecológico os assentados compartilham suas experiências e usam suas estratégias de produção para alcançar soberania alimentar nas duas pontas da relação: agricultor e consumidor.

Outra questão importante está relacionada ao interesse na realização das feiras. Como foram entrevistados apenas os assentados responsáveis pelas feiras, a figura 4 refere-se as respostas de dois entrevistados. Todavia, é possível estender essa compreensão para as demais famílias do grupo das hortas que participam dessas feiras, uma vez que aumento da renda e venda de excedente são motivaçóes que aparecem com frequência na literatura quando o assunto é comercialização da agricultura familiar.

Figura 4 - Por que o interesse em vender nas Feiras?

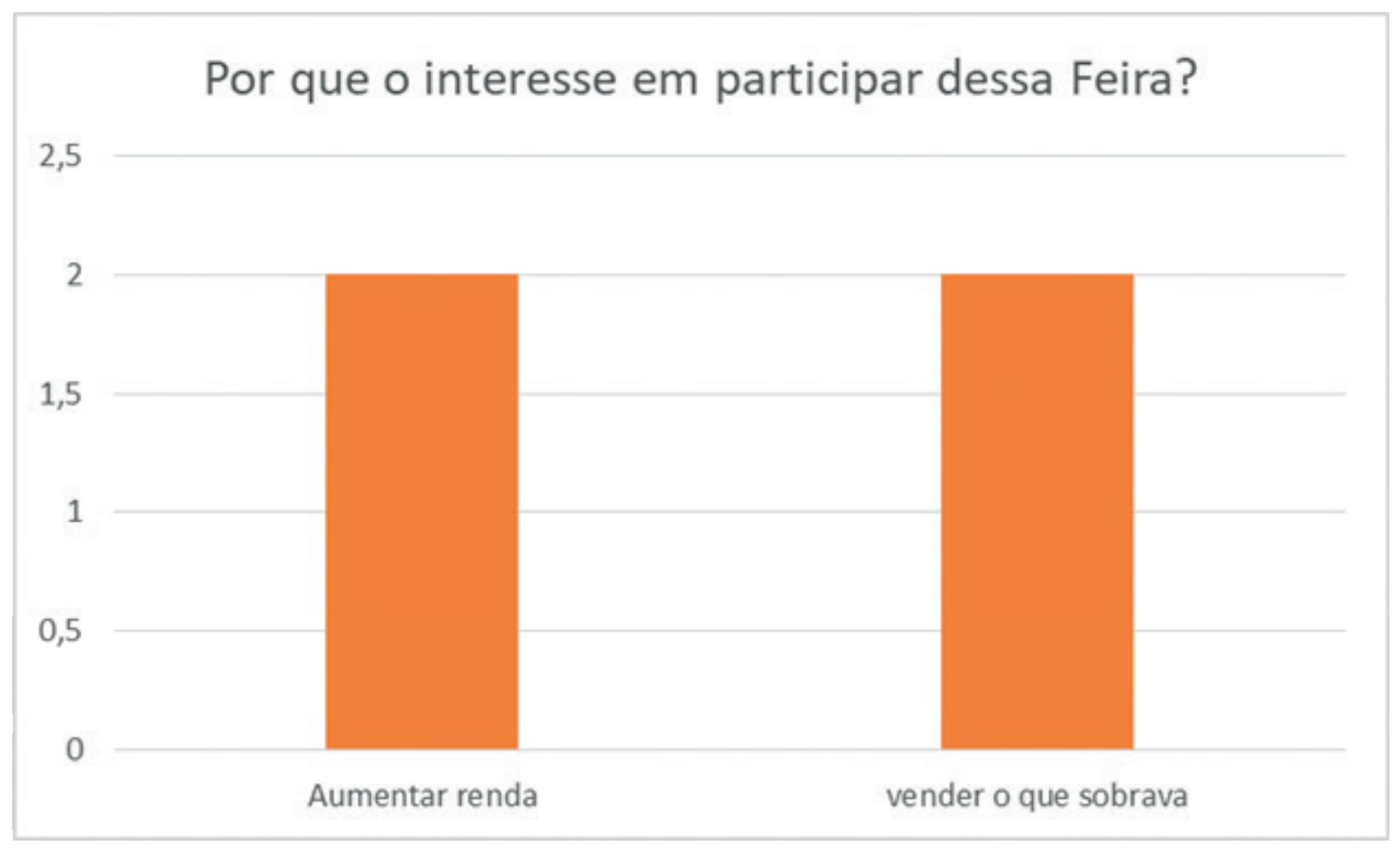

Fonte: Aplicação de questionários agricultores-feirantes. Org. Glaucimar Pinha. 
Como apresentado na figura 4, participar da Feira melhora a renda das famílias assegurando a permanência na terra. Outro aspecto importante é a venda dos produtos excedentes, evitando perdas na roça.

Igual avanço ocorreu na melhoria da comunicação com os consumidores. A relação direta permite o conhecimento entre as pessoas e, mais, a superação dos preconceitos contra os assentados, uma vez que é comum relatos sobre medo e frustaçóes geradas ao longo das experiências de acampado e assentado em Três Lagoas. Esses elementos de melhoria de renda e da comunicação com os consumidores no contexto das Feiras aparecem na tabela 1.

Tabela 1 - A feira proporcionou mudança na vida pessoal ou familiar?

\begin{tabular}{cl}
\hline Melhorou comunicação & $33 \%$ \\
\hline Obteve maior renda & $67 \%$ \\
\hline
\end{tabular}

Fonte: Aplicação de questionários agricultores-feirantes. Org. Glaucimar Pinha.

A feira na UFMS/Campus II, segundo os relatos, é o melhor lugar de venda, superando até mesmo os ganhos na Feira municipal. Os motivos seguramente são o público com maior consciência da importância da produção agroecológica e a concentração de pessoas no Campus II.

A tabela 2 mostra a média de ganho semanal da feira realizada na UFMS, Campus II.

Tabela 2 - Qual a média de ganho (reais) semanal na Feira?

\begin{tabular}{cc}
\hline LOCAL & GANHO \\
\hline UFMS/Campus II & 1,000 a 1,100 reais \\
Condomínio Don El Chall & 500 reais \\
\hline
\end{tabular}

Fonte: Aplicação de questionários nos agricultores-feirantes. Org. Glaucimar Pinha.

Em relação a dinâmica da Feira na UFMS, Campus II, o horário de maior venda é no início da feira entre $10 \mathrm{~h} 00$ às $12 \mathrm{~h} 00$. Relatam que a procura é tanta nesse período que não há tempo, às vezes, para montar a banca, os produtos vão direto das caixas para as mãos dos consumidores. A venda diminui no período da tarde, e aumenta novamente das $16 \mathrm{~h} 00$ às 19h00. Em resumo, afirmam que a feira na UFMS, Campus II, sempre é boa porque quase não sobra estoque e quando isso ocorre, encaminham para outros pontos de venda. 
Figura 5 - Qual o principal destino do ganho obtido na Feira?

\section{Qual o principal destino do ganho obtido na Feira?}

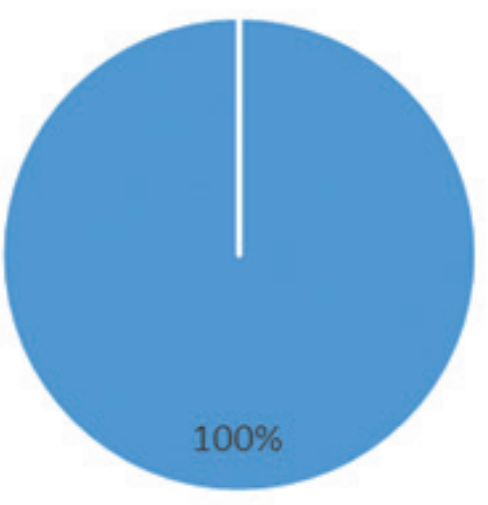

- Ajudar a renda familiar

Fonte: Aplicação de questionários agricultores-feirantes.Org. Glaucimar Pinha.

Os agricultores-feirantes preocupam-se também em produzir de acordo com a demanda e pedidos dos consumidores, respeitando a sazonalidade e tempo de maturaçáo dos alimentos - conforme princípios agroecológicos de soberania alimentar.

A Soberania Alimentar supõe novas relações sociais, libertas das determinações do capital, portanto da opressão e das desigualdades entre homens e mulheres, grupos raciais, classes sociais, sendo que o direito de acesso à terra, à água, aos recursos públicos para produzir, às sementes e à biodiversidade seja garantido para aqueles que nela produzem os alimentos, social e culturalmente definidos pelos trabalhadores, ou seja, produtores e consumidores. (THOMAZ JÚNIOR, 2007, p.12)

Por respeitar o ciclo da natureza e o trabalho em grupo, a Feira ganha em diversidade como demonstram as figuras 6 e 7 . 
Figura 6 - Produtos comprados com frequência na UFMS, CAMPUS II

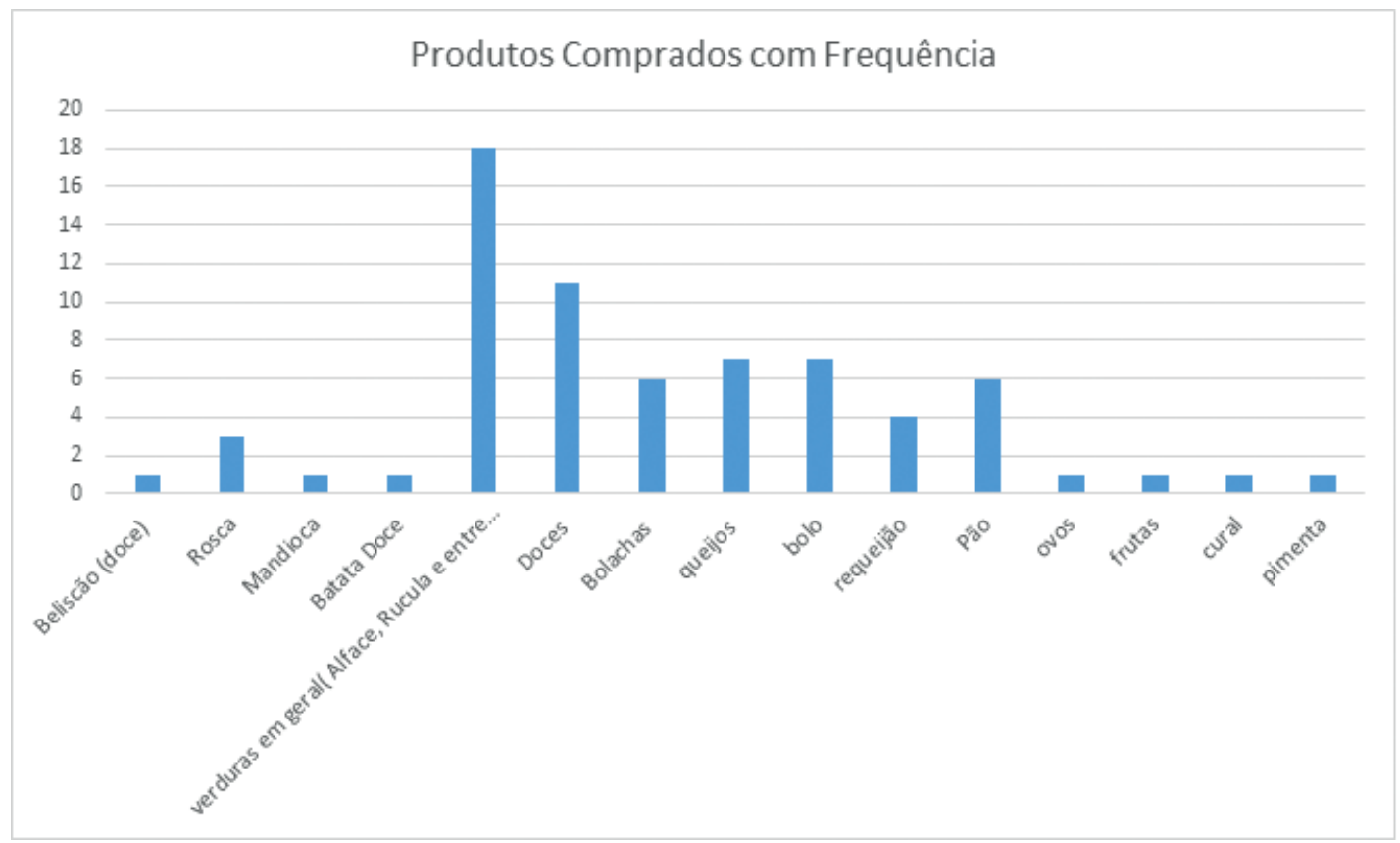

Fonte: Aplicação de questionários aos consumidores.Org. Glaucimar Pinha.

Figura 7 -: Produtos comprados com frequência no Condomínio Don El Chall

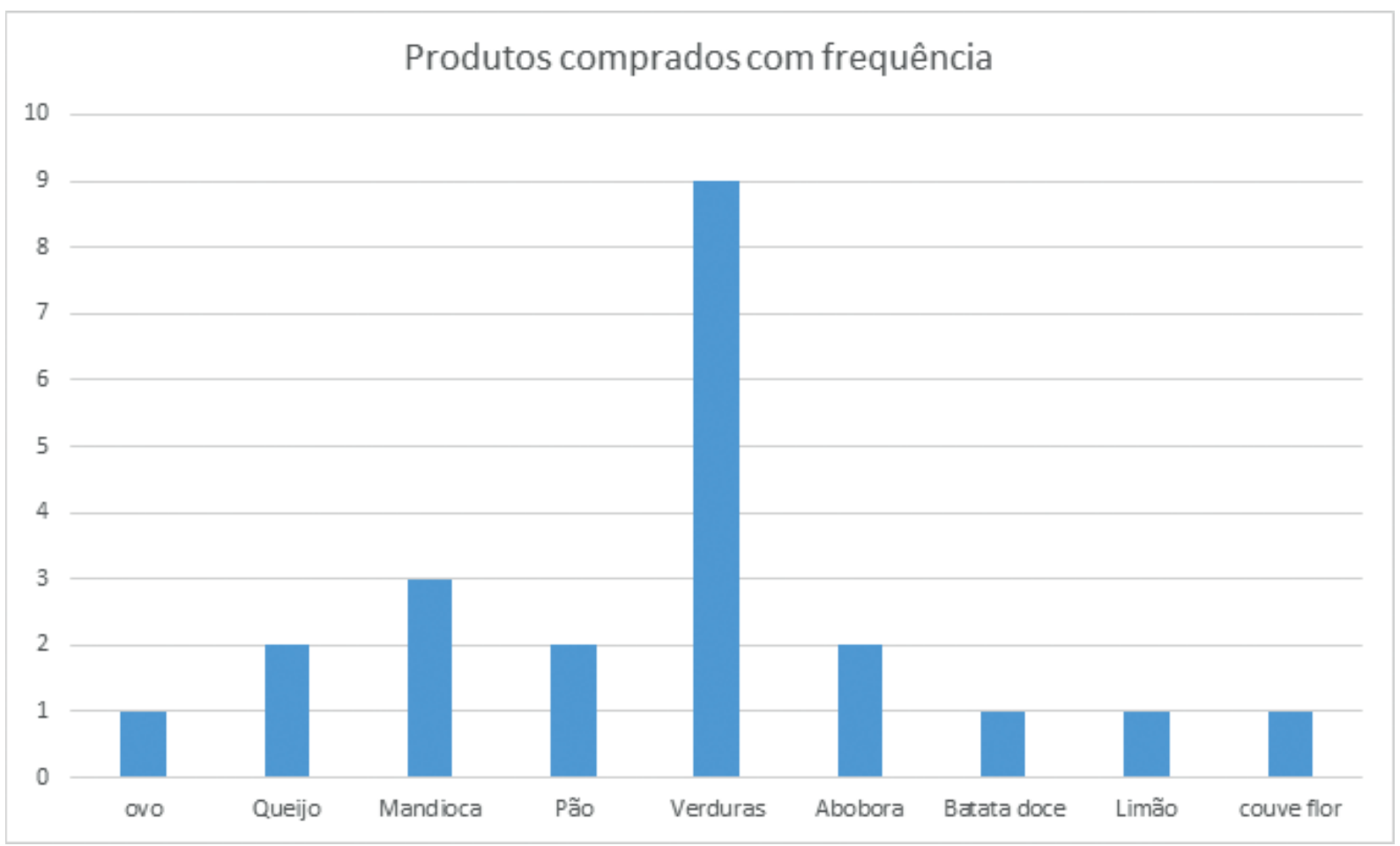

Fonte: Aplicação de questionários aos consumidores.Org. Glaucimar Pinha. 
Esta diversidade de alimentos é um dos motivos mencionado com frequência pelos consumidores que frequentam as feiras, resultando numa relação de fidelidade. As tabelas 3 e 4 revelam a constância de consumo na feira por parte do público.

Tabela 3 - Constância de consumo na feira na UFMS, CAMPUS II

\begin{tabular}{cc}
\hline TEMPO & PORCENTAGEM \\
\hline SEMANAL & $24,24 \%$ \\
\hline QUINZENAL & $42,42 \%$ \\
\hline MENSAL & $33,33 \%$ \\
\hline
\end{tabular}

Fonte: Aplicação de questionários aos consumidores da UFMS. Org. Glaucimar Pinha.

Tabela 4 - Constância de consumo na feira no Condomínio Don El Chall

\begin{tabular}{cc}
\hline TEMPO & PORCENTAGEM \\
\hline SEMANAL & $85,71 \%$ \\
QUINZENAL & $0 \%$ \\
MENSAL & $14,28 \%$
\end{tabular}

Fonte: Aplicação de questionários aos consumidores do Condomínio Don El Chall. Org. Glaucimar Pinha.

No entanto, apesar da intensa comercialização e melhoria de comunicação entre agricultores e consumidores, a origem dos assentados ainda é pouco conhecida entre os consumidores tanto da UFMS como no Condomínio, como apresentado nas tabelas 5 e 6.

Tabela 5 - Sabe quem são os agricultores feirantes na UFMS?

\begin{tabular}{cc}
\hline SIM & $30,30 \%$ \\
\hline NÃO & $69,69 \%$
\end{tabular}

Fonte: Aplicação de questionários aos consumidores da UFMS. Org. Glaucimar Pinha.

Tabela 6 - Sabe quem são os agricultores feirantes no Condomínio?

\begin{tabular}{cc}
\hline SIM & $42,85 \%$ \\
\hline NÃO & $57,14 \%$
\end{tabular}

Fonte: Aplicação de questionários aos consumidores do Condomínio Don El Chall. Org. Glaucimar Pinha.

Essa realidade aponta que ainda há um longo caminho a percorrer, pois embora as feiras na UFMS e no Condomínio Don El Chall tenham promovido uma reconexão entre agricultores e consumidores, o fato dos agricultores no Brasil serem os produtores de alimentos ainda é desconhecido e reflete na escala local - em especial, quando se trata de agricultores familiares assentados pela Reforma Agrária em Três Lagoas. 
O Caderno da Agricultura Familiar destaca a participação da agricultura familiar em algumas culturas selecionadas: produzia $87 \%$ da produção nacional de mandioca, $70 \%$ da produção de feijão (sendo $77 \%$ do feijão-preto, $84 \%$ do feijão-fradinho, caupi, de corda ou macáçar e $54 \%$ do feijão-de-cor), $46 \%$ do milho, 38\% do café (parcela constituída por 55\% do tipo robusta ou conilon e $34 \%$ do arábica), $34 \%$ do arroz, $58 \%$ do leite (composta por $58 \%$ do leite de vaca e $67 \%$ do leite de cabra), possuía 59\% do plantel de suínos, 50\% do de aves, $30 \%$ dos bovinos, e produzia $21 \%$ do trigo. A cultura com menor participação da agricultura familiar foi a soja (16\%), um dos principais produtos da pauta de exportação brasileira. (MDA, 20009, P, 26).

Além do reconhecimento de quem produz alimento, a reconexão entre o consumidor e o agricultor-feirante é de grande importância para superar no campo, e na cidade, o modelo de produção adotado na Revolução Verde que resulta em alimentos não seguros aos consumidores.

Essa necessária mudança de hábito alimentar pode ser estimulada pelas Feiras, isso fica evidente nas tabelas 7 a 10 quando questionamos se houve mudança de hábitos alimentares a partir do consumo nas Feiras.

Tabela 7 - A feira agroecológica mudou seus hábitos alimentares?

\begin{tabular}{cc}
\hline SIM & $27,27 \%$ \\
\hline NÃO & $72,72 \%$ \\
\hline
\end{tabular}

Fonte: Aplicação de questionários aos consumidores da UFMS. Org. Glaucimar Pinha.

Interessante explicar o possível paradoxo presente na tabela 7 quando $72,72 \%$ dos consumidores da UFMS declaram que náo terem mudado seus hábitos alimentares. Neste caso, é importante considerar que a Feira é continuidade de um trabalho que iniciou em 2015 com o projeto de extensão das sacolas agroecológicas, grande responsável na época pela mudança de hábito nesse grupo, como atesta Almeida (2017).

\begin{tabular}{|c|c|}
\hline TEMPO & PORCENTAGEM \\
\hline Ingerindo mais verduras & $67 \%$ \\
\hline Obtendo uma alimentação saudável & $22 \%$ \\
\hline Pelo fato de conter menos veneno & $11 \%$ \\
\hline
\end{tabular}

A Feira no Condomínio é mais recente, iniciou em 2017, situação que possivelmente explique a resposta dos consumidores, uma vez que para $71,42 \%$ a frequência na feira trouxe mudanças de hábito alimentar. 
Tabela 9 - A feira agroecológica mudou seus hábitos alimentares?

\begin{tabular}{cc}
\hline SIM & $71,42 \%$ \\
\hline NÃO & $28,57 \%$
\end{tabular}

Fonte: Aplicação de questionários aos consumidores do Condomínio Don El Chall. Org. Glaucimar Pinha.

Tabela 10 - Consequências do consumo na feira no Condomínio Don El Chall

\begin{tabular}{cc}
\hline TEMPO & PORCENTAGEM \\
\hline Ingerindo mais verduras & $28,57 \%$ \\
\hline Facilidade de obter uma alimentação saudável & $14,28 \%$ \\
Passou a ser mais saudável as refeições & $14,28 \%$ \\
Não opinou consequências & $42,85 \%$ \\
\hline
\end{tabular}

Fonte: Aplicação de questionários aos consumidores do Condomínio Don El Chall. Org. Glaucimar Pinha.

Em relação às motivaçóes que levam a participar da Feira, os consumidores apontaram: qualidade, diversidade de alimentos, segurança alimentar, preço e acessibilidade ao consumo.

Tabela 11 - Motivações para participar na Feira UFMS/Campus II

\begin{tabular}{ccccccc}
\hline Grau de satisfação & 0 a 3 & 4 a 6 & 7 a 9 & 10 & Não assinou \\
\hline Comodidade & $0 \%$ & $3,04 \%$ & $12,12 \%$ & $84,84 \%$ & $0 \%$ \\
\hline Qualidade do produto & $0 \%$ & $0 \%$ & $27,27 \%$ & $72,72 \%$ & $0 \%$ \\
\hline Preço dos produtos & $3,04 \%$ & $3,04 \%$ & $51,51 \%$ & $42,42 \%$ & $0 \%$ \\
\hline Relação aos feirantes & $3,04 \%$ & $0 \%$ & $15,15 \%$ & $81,81 \%$ & $0 \%$ \\
\hline Produção sem agrotóxico & $0 \%$ & $6,06 \%$ & $21,21 \%$ & $72,72 \%$ & $0 \%$ \\
\hline
\end{tabular}

Fonte: Aplicação de questionários aos consumidores. Org. Glaucimar Pinha.

Tabela 12 - Motivações para participar na Feira do Condomínio Don El Chall

\begin{tabular}{cccccc}
\hline Grau de satisfação & 0 a 3 & 4 a 6 & 7 a 9 & 10 & Não assinou \\
\hline Comodidade & $0 \%$ & $0 \%$ & $0 \%$ & $100 \%$ & $0 \%$ \\
\hline Qualidade do produto & $0 \%$ & $0 \%$ & $0 \%$ & $100 \%$ & $0 \%$ \\
\hline Preço dos produtos & $0 \%$ & $0 \%$ & $14,29 \%$ & $85,71 \%$ & $0 \%$ \\
\hline Relação aos feirantes & $0 \%$ & $0 \%$ & $0 \%$ & $100 \%$ & $0 \%$ \\
\hline Produção sem agrotóxico & $0 \%$ & $0 \%$ & $14,29 \%$ & $85,7 \%$ & $0 \%$ \\
\hline
\end{tabular}

Fonte: Aplicação de questionários aos consumidores. Org. Glaucimar Pinha.

\section{CONCLUSÓES}

Conclui-se que a criação das Feiras, tanto na UFMS/Campus II como no Condomínio Don El Chall, foram decisivas para a melhoria de renda dos assentados-feirantes do PA 20 de Março possibilitando reprodução social mais digna na terra. Fundamental também para os consumidores, pois a estes foi dada a opção de alimentos com qualidade e diversidade sem uso de agrotóxicos propiciando uma mudança alimentar sustentável. 
As feiras cumprem também o papel de dinamizar a economia local como apontado por Azevedo, Nunes (2003):

(...) as feiras livres municipais apresentam-se como uma excelente alternativa para os agricultores familiares venderem seus produtos diretamente ao consumidor final, com ganhos significativos para todos, estimulando assim a oferta regular de alimentos e produtos saudáveis a baixo custo e dinamização da economia local pela geração de empregos e maior circulação de mercadorias. (p. 05).

Todavia, esses espaços de Feira não são iguais, a pesquisa nos revelou que há diferença na forma de comportamento dos consumidores. Na feira realizada na UFMS, Campus II, o público de consumidores são estudantes, professores e alguns visitantes do bairro. Este público possui uma relação mais respeitosa com os assentados-feirantes e nas entrevistas demonstram maior conscientização no sentido do conhecimento sobre alimentos agroecológicos, situação que os aproxima mais do princípio da soberania alimentar. Cabe destacar que o trabalho de divulgaçáo das hortas agroecológicas e diálogo Universidade-Assentamento tem história de três anos neste espaço - ocorre desde 2015.

Por outro lado, junto ao público do Condomínio presenciamos reclamações sobre ausência de determinados produtos, sendo que a resposta dos assentados de que apenas ofertavam produtos da época pareceu pouco relevante. Situação indicadora da necessidade de um trabalho educativo mais efetivo junto a este público do Condomínio para que tenham acesso as informaçóes acerca dos princípios agroecológicos da feira. Ocorreu também reclamaçáo do tamanho considerado pequeno, no caso tratava-se de uma experiência de produção de tomates sem agrotóxicos.

Portanto, elementos como ausência de agrotóxico e adubos químicos, produção local, diversidade, a valorização do sujeito agricultor familiar, precisam ser reforçados por meio da promoção de uma nova cultura agroalimentar, do contrário reforça-se a prática da Feira como mais um serviço de comodidade.

Neste sentido, vale o alerta de Darolt (2012):

Fazer com que o consumidor perceba atributos como qualidade biológica, sabor, segurança alimentar, forma de produção, muitas vezes citados como diferencial em favor de produtos orgânicos, é um trabalho que precisa ser implementado no processo de comunicação de massa. (p. 21).

E o autor continua: "A educação para o consumo é uma das premissas para tornar o consumidor protagonista e elemento articulador de mudanças”. (DAROLT, 2012, p. 20).

Portanto, juntamente com a conquista dos espaços, a dimensão educacional se apresenta como escala essencial da Agroecologia quando consideramos o princípio da soberania alimentar, em especial no tocante a comercialização. Ou seja, o primeiro passo é consumidores terem acesso aos alimentos agroecológicos, porém não se pode parar neste patamar. É preciso estimular outros níveis, em especial o diálogo educativo entre consumidores e assentados-feirantes no sentido das trocas de conhecimento. 
La Soberanía Alimentaria da prioridad a las economías locales y a los mercados locales y nacionales, otorga el poder a los campesinos y a la agricultura familiar, la pesca artesanal y el pastoreo tradicional, y coloca la producción alimentaria, la distribución y el consumo sobre la base de la sustentabilidad ambiental, social y económica. La Soberanía Alimentaria promueve el comercio transparente, que garantice ingresos dignos para todos los pueblos, y los derechos de los consumidores para controlar su propia alimentación y nutrición. Garantiza que los derechos de acceso y la gestión de nuestra tierra, de nuestros territorios, nuestras aguas, nuestras semillas, nuestro ganado y la biodiversidad, estén en manos de aquellos que producen los alimentos. La Soberanía Alimentaria supone nuevas relaciones sociales libres de opresión y desigualdades entre los hombres y mujeres, pueblos, grupos étnicos, clases sociales y generaciones. (ROSSET; MARTINEZ-TORRES, 2012, p. 04).

\section{REFERÊNCIAS BIBLIOGRÁFICAS}

ALMEIDA, Rosemeire A. de. Dinamizando a agricultura camponesa e o consumo agroecológico em Três Lagoas-MS. Anais. VIII Simpósio Internacional de Geografia Agrária e IX Simpósio Nacional de Geografia Agrária. Curitiba, 2017. ISSN: 1980-4555.

ALMEIDA, Rosemeire A. de. A questáo agrária, internacionalização e crise agroambiental. CAMPO-TERRITÓRIO: revista de geografia agrária. Edição especial do XXI ENGA-2012, p. 1-27, jun./2014.

ALTIERI, Miguel. Agroecologia: a dinâmica produtiva da agricultura sustentável. $4^{a}$ ed. Porto Alegre: Editora da UFRGS, 2004.

AZEVEDO, Melina B. A. de, NUNES, Emanoel M. As Feiras da Agricultura Familiar: um Estudo na Rede Xique Xique nos Territórios Açu-Mossoró e Sertão do Apodi (RN). GEOTemas, Pau dos Ferros, Rio Grande do Norte, Brasil, v 3, n. 2(3), p. 59-74, jul./dez., 2013.

CRIVELLARO, C. et al. Agroecologia: um caminho amigável de conservação da natureza e valorização da vida. Núcleo de Educação e Monitoramento Ambiental - NEMA. Rio Grande: NEMA, 2008.

DAROLT, M.R. Conexáo Ecológica: novas relações entre agricultores e consumidores. Londrina: IAPAR, 2012. 162 p.

MEDEIROS, Gabriela N., ALMEIDA, Rosemeire A. Estudo da participaçáo no PAA da Associaçáo dos Agricultores Familiares do Assentamento "20 de março" em Três Lagoas/MS no tocante ao impacto na reproduçáo social das famílias associadas. Três Lagoas-MS. Relatório de Iniciação Científica (CNPq/UFMS), 2016. 
ROSSET, Peter M.; MARTÍNEZ-TORRES, Maria Elena. Movimientos Sociales Rurales y Agroecología: Contexto, Teoría y Proceso. Trad. Viviana Tipiani. Ecology and Society, v.17, n.3. Disponível em: <https://doctoradoagroecoudea.files.wordpress.com/2013/04/ movimientossocialesagroecologia.pdf> Acesso em: 20 de mai. 2017.

THOMAZ JUNIOR, Antônio. Trabalho, reforma agrária e soberania alimentar. Scripta Nova. Revista Electrônica de Geografia y Ciencias Sociales. Barcelona: Universidad de Barcelona. 1 de agosto de 2007, vol. XI, n. 245 (46). Disponível em: <http://www.ub.edu/ geocrit/sn/sn-24546.htm> Data de Acesso: 30 de Set.2018.

Recebido para publicação em abril de 2018

Aceito para publicação em maio de 2018 